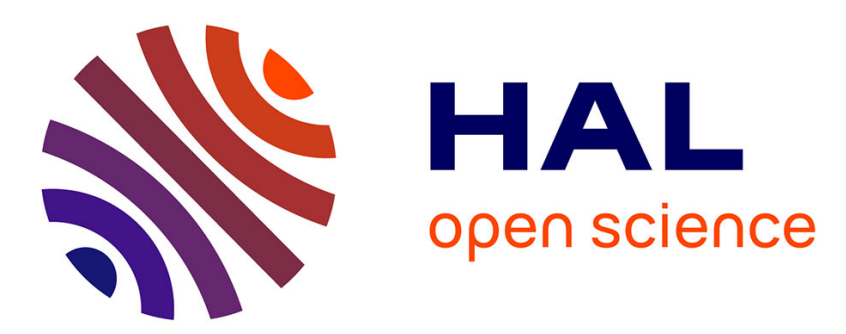

\title{
Mitochondria-associated membranes in the maintenance of cell homeostasis
}

Nadine Camougrand, Stéphen Manon

\section{To cite this version:}

Nadine Camougrand, Stéphen Manon. Mitochondria-associated membranes in the maintenance of cell homeostasis. Mitochondrial Physiology and Vegetal Molecules, pp.151 - 169, 2021, 10.1016/b978-012-821562-3.00043-5 . hal-03395328

\section{HAL Id: hal-03395328 \\ https://hal.science/hal-03395328}

Submitted on 25 Oct 2021

HAL is a multi-disciplinary open access archive for the deposit and dissemination of scientific research documents, whether they are published or not. The documents may come from teaching and research institutions in France or abroad, or from public or private research centers.
L'archive ouverte pluridisciplinaire HAL, est destinée au dépôt et à la diffusion de documents scientifiques de niveau recherche, publiés ou non, émanant des établissements d'enseignement et de recherche français ou étrangers, des laboratoires publics ou privés. 


\section{Mitochondria-Associated Membranes in the Maintenance of Cell Homeostasis. Nadine Camougrand and Stéphen Manon}

Institut de Biochimie et de Génétique Cellulaires (IBGC)

UMR5095, CNRS and Université de Bordeaux

1 Rue Camille Saint-Saëns, CS61390

Campus Carreire, 33077 Bordeaux, France

Contact: manon@ibgc.cnrs.fr; n.camougrand@ibgc.cnrs.fr

In most eukaryotic cells, mitochondria and the endoplasmic reticulum (ER) occupy a large proportion of the cytoplasm, and form intricate networks that are physically close to each other. Physical contacts between these organelles have been observed through microscopy methods since 1960 (Robertson, 1960; Franke and Kartenbeck, 1971; Morré et al., 1971). For example, up to 20\% of mitochondrial membranes is in contact with ER in HeLa cells (Rizzuto et al., 1998). However, it remained unclear for long if the formation of these contacts was regulated or if they were randomly distributed. The second question is whether they have a function in exchanges between ER and mitochondria.

Since mitochondria have a much higher density than the ER, differential centrifugation allows to separate these two organelles. However, it is well-known that the mitochondrial fraction is always "contaminated" by components from the ER (and from other subcellular compartments). Further purification by density gradient methods allowed to separate this "Mitochondria-Associated Membranes” fraction (MAM) (Meier et al., 1980), that was further characterized by a high capacity to synthesize phospholipids (Vance, 1990; Rusiñol et al., 1994). The function of MAM has first been limited to the transfer/synthesis of lipids between ER and mitochondria (Vance, 2014, for review). However, the function of MAM has been further extended to other processes involving a dialog between ER and mitochondria, namely $\mathrm{Ca}^{2+}$ signaling. Both phospholipid transfer and $\mathrm{Ca}^{2+}$ transport play a major role in fundamental cellular processes such as autophagy/mitophagy and cell death. This short review will cover the current knowledge on the links between MAM formation and stability and these fundamental cellular processes. 


\section{MAM and phospholipid synthesis and transfer}

The definitive identification of MAM as a compartment distinct from the ER bulk was based on the presence of enzymes involved in phospholipid synthesis (Vance and Schiao, 1996; Stone and Vance, 2000). In mammalian cells, full-length forms of Phosphatidylserine synthases 1 and 2 (PSS-1 and PSS2) are enriched in MAM, and largely excluded from the ER bulk (Stone and Vance, 2000). This might be related to an efficient transfer of PS to mitochondria, where PS decarboxylation is the main source of PE (Shiao et al., 1995). This did not exclude that other (truncated) forms of these enzymes were present in other parts of the ER, providing PS to this organelle. A similar process of localized PS

synthesis in MAM has been observed in yeast (Achleitner et al., 1999). Other enzymes involved in phospholipid synthesis have a dual localization between MAM and the ER bulk, such as liver Phosphatidylethanolamine N-methyl Transferases, that convert PE to PC (Vance et al., 1997). In this case, two distinct isoenzymes (PEMT1 and PEMT2) are involved. Following these pioneering studies, a growing number of lipid syntheses have been found to take place in MAM, such as ceramide (Stiban et al., 2008) and triacylglycerol (Stone et al., 2009). In yeast, PE can be synthesized from Lyso-PE by the Acyltransferase Ale1, located in MAM (Riekhof et al., 2007), suggesting that this localization of lipid syntheses is conserved among different pathways and organisms. Indeed, the localization of lipid syntheses in MAM has been connected to the requirement for an efficient transfer of ER-synthesized lipid to mitochondria (Tatsuta et al., 2014). One can intuitively imagine that the transport of hydrophobic lipids from ER to mitochondria through the aqueous cytosolic phase is not energetically favorable. A vesicular transport of lipid may occur, but has not been observed so far between ER and mitochondria. Lipid transfer proteins exist, and are involved in the transport of ceramide between ER and Golgi (Hanada et al., 2003), but have not been found for mitochondria. The existence of MAM offers a support for the diffusion of lipid between the donor membrane (ER) and the acceptor membrane (Outer Mitochondrial Membrane, OMM) through close junctions. PS synthesis by PSS located in MAM would therefore be channeled to PE synthesis through PSD located in mitochondria. Conversely, mitochondrial PE could be "re-exported" and converted to PC through PEMT in MAM. Given the localization of PSD in the matrix (but probably close to the inner mitochondrial membrane, IMM), it is likely that a component of the OMM (not identified yet) or contacts sites between OMM and IMM are also involved. The possible connection between MAM and OMM/IMM contact sites is thus an exciting issue. Mitochondrial contact sites are enriched with negatively charged phospholipids, namely cardiolipin, that is specific to mitochondria (Hoch, 1992; Schlattner et al., 2014, for reviews). 
The architecture of the contact sites is stabilized by a complex called MICOS, both in yeast (Harner et al., 2011; Horvath and Daum, 2013) and human cells (Kozjak-Pavlovic, 2017, for review) that is involved in the exchange of cardiolipin, PA and probably other phospholipids between OMM and IMM. To date, there is no structural evidence that MAM and mitochondrial contact sites are physically connected but the transfer of neosynthesized PS in MAM to the IMM/matrix PSD makes it likely. Other lipids, such as sterols, also might be transported by a similar system from the ER to mitochondria. Indeed, sterols are synthesized in the ER and are transported to other membranes by specific transporters (Sullivan et al., 2006) and there is no direct evidence of enrichment of sterol synthesis enzymes in MAM compared to bulk ER. However, sterol transport to the IMM (mostly as a substrate for steroid hormones synthesis) occurs through a complex spanning the two mitochondrial membranes and including TSPO, VDAC1 and ANT1 (Gatliff and Capanella, 2012, for review) thus stabilizing a contact site between OMM and IMM. How this type of contact site might or not be connected to MAM is an interesting issue.

\section{The yeast ERMES complex}

In yeast, a genetic screen allowed to identify the complex ERMES (ER-mitochondria encounter structure) as required for the tethering between ER and mitochondria in yeast (Kornmann et al., 2009). ERMES is a complex composed of at least four proteins: OMM proteins Mdm10 and Mdm34, ER membrane protein Mmm1, and cytosolic protein Mdm12. Mutations in ERMES components cause diverse mitochondrial phenotypes, including mitochondrial morphology defects and the inability of cells to grow on a non-fermentable carbon source. These phenotypes can be reversed by the expression of an artificial tether, suggesting that the main function of the complex is to act as a mechanical link between ER and mitochondria. Considering the pleiotropic effect of ERMES alterations, it was likely that a fundamental maintenance process, such as phospholipid homeostasis, was affected. Indeed, Mmm1, Mdm12 and Mdm34 contain a SMP domain that is closely related to the lipid-binding domain Tulip (Kopec et al., 2010; Michel and Kornmann, 2012). The structure of the Mmm1-Mdm12 subcomplex show that it forms a hydrophobic tunnel allowing the diffusion of phospholipids (Jeong et al., 2017). It is therefore likely that ERMES is directly involved in the transfer of lipids between ER and MOM. The fact that the deletion of Mmm1, Mdm12 or Mdm10 dramatically alter mitochondrial function and render yeast cells unable to grow on a non-fermentable carbon source, with a concomitant 
loss of mitochondrial DNA (Tan et al., 2013), pointed at the importance of this ER-mitochondria lipid transfer process.

No obvious homologous structure of the ERMES complex has been identified in mammalian cells. However, the yeast GTPase Gem1 is also associated to ERMES and regulates MAM stability (Kornmann et al, 2011). Gem1 is the yeast homolog of the mammalian protein Miro that forms foci at the contacts between ER and mitochondria (Kornmann et al., 2011). Recently, Miro clusters have been found to regulate ER-mitochondria contacts, with further effects on mitochondrial transport and cristae organization (Modi et al., 2019). This suggests that the molecular organization of MAM involved in lipid transfer might be conserved between yeast and mammals, although other mammalian components remain to be identified.

\section{MAM and $\mathrm{Ca}^{2+}$ signaling}

$\mathrm{Ca}^{2+}$ movements between ER and mitochondria are crucial to cell fate. Indeed, $\mathrm{Ca}^{2+}$ is required for the activity of several Krebs cycle enzymes, such as pyruvate dehydrogenase, $\alpha$-ketoglutarate dehydrogenase and isocitrate dehydrogenase (Denton and McCormack, 1986; Hansford, 1994). Conversely, high intramitochondrial concentrations of calcium are responsible for the opening of the mitochondrial permeability transition pore (mPTP) (Giorgio et al., 2018, for a recent review). mPTP opening initiates necrotic cell death following, namely, ischemia/reperfusion (Baines et al., 2005; Nakagawa et al., 2005).

Local intramitochondrial calcium concentration was shown to be higher in the regions close to ERmitochondria contacts (Rizzuto et al., 1998). It has been postulated that the mitochondrial calcium uniporter (MCU) could be physically close to the ER calcium transporter IP3R and the OMM VDAC (Szabadkai et al., 2006), thus allowing a calcium channeling process that would increase the efficiency of ER-mitochondria $\mathrm{Ca}^{2+}$-signaling (Pizzo and Pozzan, 2007). Strikingly, the isoform III of IP3R (Mendes et al., 2005), The ER calcium sensor Sigma-1 receptor (Hayashi and Su, 2007), and Grp75 (Szabadkai et al., 2006) were found to be enriched in MAM and to contribute to the ER-mitochondria calcium transport. This does not imply that this localization and function are exclusive, but more likely suggests that close ER-mitochondria contacts dependent on these proteins might form in a transitory manner to efficiently channel calcium when needed (Shkryl and Shirokova, 2010; Csordas et al., 2010). Considering the role of $\mathrm{Ca}^{2+}$ in necrotic cell death, the role of MAM in this type of death is related to the above-mentioned $\mathrm{Ca}^{2+}$-channeling between ER and mitochondria. Local elevated mitochondrial 
$\mathrm{Ca}^{2+}$ concentration at the vicinity of ER-mitochondria contact sites containing IP3R, VDAC and MCU would trigger the opening of the mPTP, massive release of mitochondrial molecules (including $\mathrm{Ca}^{2+}$, in the process called "calcium-induced calcium release"), loss of mitochondrial energetic processes, and ultimately cell death (Giorgio et al., 2018, for review). mPTP components have for long been identified as being VDAC on the OMM and ANT on the IMM. This is now largely regarded as wrong, and the exact identity of mPTP components is still discussed (Baines and Gutierrez-Aguilar, 2018, for review). Most recent experiments point at the involvement of ATP synthase dimers (Carraro et al., 2019, for review), but it is not known if the localization of these dimers has something to do with mPTP regulation by calcium.

\section{MAM and apoptotic cell death}

Until the demonstration that the loss of cyclophilin D, a major regulator of mPTP, did not impair apoptotic cell death (Nakagawa et al., 2005), it was believed that mPTP opening was also directly involved in apoptosis (Jacotot et al., 1999). This mistake was largely due to the fact that mammalian cells in culture engaged into a secondary necrosis (mPTP-dependent) following the initial apoptotic signal (mPTP-independent), because of the absence of elimination of apoptotic cells by the immune system.

It is now largely accepted that the permeabilisation of the OMM during apoptosis is due to the formation of large channels formed of oligomers of Bax (Pavlov et al., 2001) and Bak (Bleicken et al., 2013), the pro-apoptotic members of the Bcl-2 family. These large channels allow the release of apoptogenic factors from the intermembrane space to the cytosol (Renault and Manon, 2011; Birkinshaw and Czabotar, 2017, for reviews). Bax and Bak are regulated by the other members of the Bcl-2 family at different levels. The anti-apoptotic proteins Bcl-2, Bcl-xL and Mcl-1 prevent their activation. For long, the "rheostat" model considered that the formation of e.g. Bax/Bcl-2 dimers allowed to sequester Bax away from mitochondria and that the rupture of the interaction (by a BH3only protein such as Bad) was sufficient to promote Bax mitochondrial relocation and activation (Korsmeyer et al., 1993). Although this view is still partly valid, it was largely incomplete (Volkmann et al., 2014). First it did not explain the regulation of Bak, that is constitutively mitochondrial, where it is maintained under an inactive state by the interaction with VDAC2 (Cheng et al., 2003). Also, the overexpression of Bcl-2 (Teijido and Dejean, 2010) or Bcl-xL (Renault et al., 2015) tends to increase the localization of inactive Bax at the mitochondria in non-apoptotic cells. The process of translocation/ 
retrotranslocation, that is controlled not only by anti-apoptotic proteins (Edlich et al., 2011), but also by protein kinases such as AKT (Schellenberg et al., 2013), adds to the complexity of the regulation. Ultimately, the distribution of Bax in different compartments seems to be a more crucial determining factor in the capacity of a cell to engage into apoptosis than its capacity to oligomerize (Kuwana et al., 2020).

Conversely, BH3-only proteins tBid, Bim and Puma activate Bax and Bak, either directly, or indirectly through the inhibition of anti-apoptotic proteins (Shamas-Din et al., 2011, for review). It is now largely accepted that there is a dynamic equilibrium of the repartition of all different Bcl-2 family members (pro-apoptotic, anti-apoptotic, BH3-only) between the cytosol and the OMM (Edlich, 2018). However, these proteins have also been found in the ER, such as Bax (Zong et al., 2003; Gajkowska et al., 2004; Stout et al., 2007; Zhang et al., 2013), Bcl-2 (Gotow et al., 2000; Annis et al., 2001; Thomenius et al., 2003) and Bcl-xL (Eno et al., 2012) (Popgeorgiev et al., 2018, for review). ER-localized Bcl-2 regulates $\mathrm{Ca}^{2+}$ transport (Lam et al., 1994; He et al., 1997; Foyouzi-Youssefi et al., 2000): actually, this connection between its ER-localization and calcium-regulated cell death was described even before its inhibitory function on Bax activation. This effect might also happen with Bcl-xL (Williams et al., 2016). Conversely, ER-localized Bax was found to stimulate $\mathrm{Ca}^{2+}$ fluxes that trigger cell death (Oakes et al., 2003). It was also found that the zebrafish pro-apoptotic protein Bcl-w regulated both VDAC and MCU to control $\mathrm{Ca}^{2+}$ flow into mitochondria (Prudent et al., 2013). Consequently, both pro- and antiapoptotic proteins modulate calcium-induced death (i.e. necrosis), indirectly, through their capacity to modulate ER calcium. Considering the importance of MAM in calcium-induced death, the question of a MAM localization of Bcl-2 family members is fully relevant.

It has been observed that the cytomegalovirus anti-apoptotic protein vMIA induced a re-targeting of Bax to MAM, instead of OMM (Zhang et al., 2013). This re-targeting prevents mitochondria permeabilization and Bax is further degraded by the proteasome. Proteins of the Bcl-2 family can be ectopically expressed in yeast, where they keep their ability to localize and permeabilize the OMM (Renault an Manon, 2011, for review). When human Bax was expressed in yeast cells carrying a deletion in a ERMES protein (Mdm34), the protein was less capable to reach the OMM (Légiot et al., 2019). These data suggest that MAM might be a transitory location for Bax, where it might be blocked if an anti-apoptotic signal (such as vMIA) is present. According to the Bax translocation/retrotranslocation processes (Edlich et al., 2011; Schellenberg et al., 2013, Renault et al., 2015), one can speculate that MAM stability might have a crucial role in the cycling of Bax between 
mitochondria (where it can be activated to promote apoptosis) and the ER (where it cannot be activated), providing an additional level of regulation of Bax function and apoptosis.

Ceramide, like PS, are synthesized in MAM, and can be transferred to the OMM following an apoptotic signal (Stiban et al., 2008). They are able to permeabilize OMM to apoptogenic factors, alone or in combination with Bax, in a way sensitive to Bcl-2/Bcl-xL (Colombini, 2017, for review).

Interestingly, ERMES also regulates acetic acid-induced death in yeast where calcium, Bcl-2 family members, or ceramides are not involved (Martins et al., 2019), suggesting that ER-mitochondria contacts are involved in many other death signaling processes.

\section{MAM and Autophagy/Mitophagy}

Autophagy is a degradation process, highly conserved among eukaryotes, by which cytosolic components such as organelles or proteins are degraded within specific compartments: the vacuole in yeast and plants, and lysosomes in mammalian cells. It involves de novo formation of double phospholipid membranes called phagophore, that elongate, close and form autophagosomes containing sequestered portions of cytosol and organelles. Mature autophagosomes merge with vacuole or lysosomes and the cargo is degraded by the hydrolytic enzymes. Degradation products are re-exported to the cytosol and reused by the cell (Xie and Klionsky, 2007).

The molecular mechanisms involved in autophagy have been widely studied, and this process has been increasingly understood both in yeast and mammalian cells. Autophagy requires more than 40 autophagy-related genes (denoted 'Atg') proteins. Among them, LC3/Atg8 plays a central role, being localized from the beginning until the end of the process in the membranes of the autophagosomes, through the conjugation of a PE at the C-ter end of the protein (Chimera et al., 2000).

Mitophagy allows selective degradation of mitochondria by autophagy, and is involved in quality control of mitochondria (Lemasters, 2005). This came from a work on S.cerevisiae, grown on a nonfermentable carbon source (lactate) and subjected to nitrogen starvation (Kiššová et al., 2004).

Multiple mitophagy programs either operate independently or undergo crosstalk and require modulated receptor activities in the mitochondrial membranes. In mammalian cells, two main mechanisms of mitophagy signaling have been identified: ubiquitin-mediated mitophagy and receptor-mediated mitophagy. In these pathways, ubiquitin or proteins, receptors or adaptors, containing a LC3-interacting domain (LIR), act to recruit LC3 family members to mitochondria and thus induce mitophagy. The mechanisms and factors involved in these mitophagy pathways are discussed thereafter. 


\section{PINK1/Parkin-dependent mitophagy}

Ubiquitin-mediated mitophagy relies on ubiquitin chains made by E3 ligases to operate as the 'destroy me’ signal. The best-characterized ubiquitin-mediated mitophagy pathway involves PINK1 and Parkin. PINK1 (PTEN-induced putative kinase 1) (park6) and PARKIN (park2) are two mutated genes in Parkinson's disease (Gasser, 2005). Under basal conditions, PINK1 goes through the TOM complex due to its N-terminal mitochondrial-targeting sequence (MTS), and is processed by PARL in the IMM and rapidly degraded by the proteasome (N-end rule pathway). PINK1 is barely detectable due to its quick turnover (Matsuda et al., 2010; Narendra et al., 2008; Narendra et al., 2010). At the same time, the E3 ubiquitin-ligase Parkin is kept in the cytosol in an auto-inhibited state, through multiple intramolecular interactions (Chaugule et al., 2011). When mitochondria undergo damage such as loss of membrane potential, PINK1 stays anchored and accumulates in the OMM. Once PINK1 is stabilized to mitochondria, it phosphorylates Parkin on serine 65 (pS65-Parkin). pS65-Parkin is recruited to mitochondria, changes conformation and gets activated, resulting in an increase of its ubiquitin ligase activity. At the same time, PINK1 phosphorylates ubiquitin resulting in more Parkin recruitment and activation, amplifying the process. Polyubiquitinated mitochondrial proteins are recognized by adaptor proteins such as p62 (also known as Sequestosome-1/SQSTM1), OPTN (Optineurin), TAX1BP1 (Tax1 binding Protein 1), NDP52 (Nuclear dot protein 52kDa) and NBR1 (Pankiv et al., 2007; Kirkin et al., 2009; Wild et al., 2011). Phagophore initiation and elongation machineries are recruited to these highly ubiquitinated mitochondrial areas, resulting in mitochondria engulfment into autophagosomes and further lysosomal degradation.

\section{PINK1/Parkin-independent mitophagy, specific receptor characterization}

Mitophagy events have also been reported when PINK1/Parkin proteins were dispensable. PINK1/Parkin-independent mitophagy relies on receptors located in the OMM. Several receptors have been characterized so far: FUNDC1 (Liu et al., 2012), NIX/BNIP3L (Novak et al., 2010; Zhu et al., 2013), BCL2L13 (Murakawa et al., 2015), and prohibitin 2 (PBH2) (Wei et al., 2017). All these receptors contain a LIR domain and can bind LC3 proteins. FUNDC1 and BNIP3 receptors are dephosphorylated and phosphorylated upon membrane potential loss and hypoxia respectively, resulting in an increase of LC3 affinity. In S.cerevisiae, the mitochondrial receptor Atg32p is phosphorylated when mitophagy is induced. The human BCL2L13 protein may be homolog to Atg32p. 
Indeed, ectopic expression of BCL2L13 in the atg32 $\Delta$ yeast mutant can rescue mitophagy, thereby reinforcing its role as a mitophagy receptor (Murakawa et al., 2015). NIX and BNIP3 are involved in both mitophagy and apoptosis (Novak et al., 2010; Zhu et al., 2013). NIX is implicated in erythrocyte maturation by promoting mitochondrial elimination and acts as a mitophagy receptor recognized by autophagy machinery (Schweers et al., 2007; Sandoval et al., 2008). It is involved in autophagy induction and Parkin translocation to mitochondria (Ding et al., 2010). BNIP3L could also be ubiquitinated by Parkin and induce mitophagy (Gao et al., 2015). The pro-autophagic protein AMBRA1 can interact with LC3 protein and promote mitophagy in Parkin knock-down cells (Strappazzon et al., 2015). These results show the high level of complexity in mitochondrial degradation, and that mitophagy is far from being a linear event.

Recently, prohibitin 2 (PHB2), an IMM protein, was identified as a crucial mitophagy receptor involved in mitochondrial targeting for autophagic degradation (Wei et al., 2017). PHB2 binds LC3 through the LIR domain upon mitochondrial depolarization and proteasome-dependent OMM rupture. PHB2 is required for Parkin-induced mitophagy in mammalian cells and for the clearance of paternal mitochondria after embryonic fertilization in C.elegans (Wei et al., 2017).

In mammalian cells, mitophagy can also be triggered by hypoxia (Liu et al., 2012). In this situation, FUNDC1, a mitochondrial outer-membrane protein, is a receptor of selective mitophagy through its interaction with LC3.

The role of cardiolipin in mitophagy induction was characterized in neuronal cells (Chu et al., 2013). After treatments with mitophagy inducers (rotenone, staurosporine, 6-hydroxydopamine,...), cardiolipin is translocated from the IMM to the OMM and can interact with LC3. This translocation could be one of the signals of mitophagy induction.

\section{Role of MAM in providing membranes and PE for autophagy/mitophagy processes}

Many studies in yeast and mammalian cells have shown that different cellular compartments, such as mitochondria (Hailey et al., 2010), the Golgi (Van der Vaart et al., 2010), ER (Axe et al., 2008) and the plasma membrane (Ravikumar et al., 2010) may supply autophagosome membranes. However, the interplay between ER and mitochondria in autophagy has been highlighted in recent studies. Indeed, in starved cells, autophagosomes are derived from OMM (Hailey et al., 2010). The transient localization of the early autophagosomal marker, Atg5, in puncta formed on the surface of mitochondria was observed, followed by LC3-positive autophagosomes transiently associated with mitochondria. This 
was confirmed by the use of the fluorescent lipid, NBD-PS (which converts to PE in mitochondria) that transfers from mitochondria to autophagosomes in starved cells. In addition, when mitochondria/ER connections are perturbed by loss of mitofusin2, starvation-induced autophagosomes do not form. (Hailey et al., 2010). These observations were subsequently confirmed by showing that autophagosomes form at ER-mitochondria contact site in mammalian cells. Imaging data reveal that both the pre-autophagosome/autophagosome marker ATG14 (or ATG14L) and the autophagosomeformation marker ATG5 relocalize to ER-mitochondria contact sites after starvation, until formation is complete. Subcellular fractionation showed that ATG14 co-fractionates in MAM under starvation conditions. Disruption of the ER-mitochondria contact site prevents the formation of ATG14 puncta. The ER-resident SNARE protein syntaxin 17 (STX17) binds to ATG14 and recruits it to the ERmitochondria contact site (Hamasaki et al., 2013). STX17 also regulates the localization of the fission protein DRP1. All these data are confirmed by a series of biochemical and molecular analyses carried out in human fibroblasts in order to characterize lipid rafts in MAM and to explore their possible implication in autophagosomes formation. In this study, the presence of lipid microdomains containing ganglioside GD3 has been detected in MAM, and an interaction of this lipid with core-initiator proteins of autophagy, such as AMBRA1 and WIPI1, was observed. This association seems thus to take place in the early phases of autophagy in which MAM have been hypothesized to play a key role (Garofalo et al., 2016).

In nitrogen starved yeast, the mitochondrial phosphatidylserine decarboxylase Psd1, leading to the

synthesis of PE from PS, is required for the mitophagy process (Vigié et al., 2018). As highlighted above, the role of MAM acting as bridges between mitochondria and ER is crucial for this transfer.

\section{MAM components and autophagy/mitophagy}

In yeast, mutants lacking ERMES subunits, $\Delta m d m 10, \Delta m d m 12, \Delta m d m 34$, and $\Delta m m m 1$, showed severe mitophagy defects but are not affected in bulk autophagy. ERMES contributes to mitophagy at the step of isolation membrane formation (Böcker and Westermann, 2014). Moreover, Mdm12 and Mdm34 colocalize with two actors of mitophagy, Atg11 and Atg32, during its induction (Mao et al., 2013). Recently, it was shown that Mdm34 and Mdm12, are ubiquitinated by the E3 ligase Rsp5. This ubiquitination did not affect mitochondrial dynamics nor ERMES turnover, but was required for efficient mitophagy (Belgareh-Touze et al., 2017). 
IP3R blockade triggered the autophagy of both ER and mitochondria, as exactly observed in starvationinduced autophagy. The IP3R is known to reside in the membranes of the endoplasmic reticulum (ER) as well as within ER-mitochondrial contact sites. The autophagic pathway triggered by IP3R inhibition follows a canonical pathway because it requires the obligate contribution of Beclin-1, Atg5, Atg10, Atg12 and hVps34 (Criollo et al., 2007; Cardenas et al., 2010).

The relocalization of the tumor suppressor promyelocytic leukemia protein (PML) at MAM negatively controlled autophagosome formation and, thus, autophagy induction (Missiroli et al., 2016).

It has also been shown that the integral ER protein vesicle-associated membrane protein-associated protein B (VAPB) binds to the OMM protein, protein tyrosine phosphatase interacting protein 51 (PTPIP51) to participate to MAM formation (Stoica et al., 2014). Modulating expression of VAPB or PTPIP51 affects $\mathrm{Ca}^{2+}$ exchange between the two organelles. Then, the manipulation of VAPB and PTPIP51 expression (that modulated ER-mitochondria association) impacted both basal and induced autophagy (Gomez-Suaga et al., 2017). Moreover, this study showed that the impact of modulation of ER-mitochondria tethering is dependent on how autophagy is induced by rapamycin or by starvation. There are, however, some differences between these various studies. Notably, loosening ERmitochondria contacts induces autophagosome formation, whereas some others report that such

loosening is inhibitory to their formation (Hailey et al., 2010 ; Hamasaki et al., 2013 ; Garofalo et al., 2016). The reasons for these dissimilar results may involve different experimental approaches.

Phosphofurin acidic cluster sorting 2 (PACS2) regulates ER-Mitochondria communications, ER apoptosis and homeostasis. It was demonstrated that the successful autophagy of dysfunctional mitochondria stimulates VSMCs (Vascular smooth muscle cells) survival against pro-apoptotic oxidized lipoproteins (Swiader et al., 2016) whereas defective autophagy promotes VSMC apoptosis and unstable atherosclerotic plaque phenotype. Then, by using high-resolution fluorescence methods (STED confocal microscopy and proximity ligation assay), Moulis et al. (2019) showed an increase in mitochondria-ER contacts in stressed VSMCs, and the involvement of PACS-2 to establish those organelle contacts. Indeed, the disruption of ER-mitochondrial contacts by knocking down PACS-2 impairs mitophagosome formation and favors oxidized lipoproteins-induced cell apoptosis. These data support the hypothesis that MAM integrity is a prerequisite for mitochondria autophagy in mammalian cells.

\section{Localization/Relocalization of autophagy/mitophagy actors on MAM}


Some actors of the core autophagic machinery are found in MAMs, such as Atg14, Atg8, Atg5 or WIPI. In addition, some mitochondrial proteins involved in mitophagy, located in mitochondria, have also been found in MAM. It has been shown that PARKIN could be recruited by Beclin1 in the cytosol and translocated to damaged mitochondria (Choubey et al., 2014). Beclin1 is a key component of the class III phosphatidylinositol 3-kinase (PtdIns3K) complex (including Beclin, ATG14, PIK3C3/Vps34 and PIK3R4/Vps15 (Funderburk et al., 2010)), that is required for the initiation of autophagosome formation and relocalizes to MAM upon starvation-induced autophagy (Hamasaki et al., 2013). Also, after mitophagy induction, both Beclin1 and PINK1 relocalize at ER-mitochondria contact sites, promoting ER-mitochondria tethering and autophagosome formation (Gelmetti et al., 2017). CCCP treatment also increased ER-mitochondria tethering, that was abolished in either Beclin1 or PINK1 is silenced. PARKIN further translocated to mitochondria in a PINK1-dependent fashion, and was particularly enriched in MAM (Gelmetti et al., 2017). This confirmed previous observations that PARK2 accumulates both at mitochondria and ER-mitochondria junctions in conditions of excitotoxicity (Van Laar et al., 2015). The finding that PINK1, PARK2 and BECN1 all localize at MAM after CCCP treatment had never been observed previously. However, while PARK2 and BECN1 are dispensable for each other translocation at MAM, both proteins require PINK1.

FUNDC1 is a mitochondrial receptor that is involved in hypoxia induced mitophagy. In hypoxic cells, it is also accumulated at ER-mitochondria contact sites by interacting with the ER membrane protein calnexin in hypoxic cells (Wu et al., 2016). FUNDC1 is specifically required for mitochondrial fragmentation by recruiting DRP1 to drive mitochondrial fission in response to hypoxic stress (Wu et al., 2016). Moreover, MFN2, a protein required for mitochondria fusion and also participating in tethering between ER and mitochondria, could be a substrate for PINK1 (de Brito and Scorrano, 2008). All these data indicate that a close link exists between MAM and autophagy/mitophagy and that MAM play a role of platform for the formation of autophagosomes and for the course of autophagy and mitophagy in cell survival.

\section{Concluding remarks}

This short overview highlights the dual nature of MAM, that fuels mitochondria with lipid and $\mathrm{Ca}^{2+}$, but also initiates autophagy/mitophagy (that degrade mitochondria to sustain cell survival) and death pathways (that degrade cells to sustain organism survival). It is likely that these different pathways do

not involve the same type of MAM. MAM containing lipid synthesis enzymes are probably not the 
same MAM that contain IP3R or the Bcl-2 family members. However, some of the processes that depend on MAM are likely connected. For example, PS synthesis leading to PE generation and PEdependent autophagosome formation most probably occur in the same membranes. Another example could be the synergic effect of ceramide and Bcl-2 family members leading to OMM permeabilization during the ealy steps of apoptosis. Consequently, each process involving a communication between ER and mitochondria may rely on a specific type of MAM, that is specific in terms of biochemical composition, but might also be specific in terms of morphology of contacts (Giacomello and Pellegrini, 2016). A recent original study allowed to identify new MAM components that had not been found before (Kwak et al., 2020). The actual function of these components in ER-mitochondria contacts and communication remains a vast domain to explore. 


\section{References}

Achleitner G, Gaigg B, Krasser A, Kainersdorfer E, Kohlwein SD, Perktold A, Zellnig G, Daum G. Association Between the Endoplasmic Reticulum and Mitochondria of Yeast Facilitates Interorganelle Transport of Phospholipids Through Membrane Contact. Eur J Biochem 1999; 264(2):545-53

Annis MG, Zamzami N, Zhu W, Penn LZ, Kroemer G, Leber B, Andrews DW. Endoplasmic reticulum localized Bcl-2 prevents apoptosis when redistribution of cytochrome c is a late event. Oncogene 2001;20(16):1939-52

Axe EL, Walker SA, Manifava M, Chandra P, Roderick HL, Habermann A, Griffiths G, Ktistakis NT. Autophagosome formation from membrane compartments enriched in phosphatidylinositol 3phosphate and dynamically connected to the endoplasmic reticulum. J Cell Biol 2008;182:685-701

Baines CP, Kaiser RA, Purcell NH, Blair NS, Osinska H, Hambleton MA, Brunskill EW, Sayen MR Gottlieb RA, Dorn II GW, Robbins J, Molkentin JD. Loss of cyclophilin D reveals a critical role for mitochondrial permeability transition in cell death. Nature 2005;434(7033):658-62

Baines CP, Gutiérrez-Aguilar M. The Still Uncertain Identity of the Channel-Forming Unit(s) of the Mitochondrial Permeability Transition Pore. Cell Calcium 2018;73:121-130

Belgareh-Touze N, Cavellini L, Cohen MM. Ubiquitination of ERMES components by the E3 ligase Rsp5 is involved in mitophagy. Autophagy 2017; 13:114-32

Birkinshaw RW, Czabotar PE. The BCL-2 family of proteins and mitochondrial outer membrane permeabilisation. Semin Cell Dev Biol 2017;72:152-62

Bleicken S, Landeta O, Landajuela A, Basañez G, García-Sáez AJ. Proapoptotic Bax and Bak Proteins Form Stable Protein-Permeable Pores of Tunable Size. J Biol Chem 2013;288(46):33241-52

Böckler S., Westermann B. Mitochondrial ER contacts are crucial for mitophagy in yeast. Dev Cell 2014;28:450-8 
Cárdenas C, Miller RA, Smith I, Bui T, Molgó J, Müller M, Vais H, Cheung KH, Yang J, Parker I. Essential regulation of cell bioenergetics by constitutive InsP3 receptor $\mathrm{Ca}^{2+}$ transfer to mitochondria. Cell 2010;142:270-83

Carraro M, Checchetto V, Szabó I, Bernardi P. F-ATP synthase and the permeability transition pore: fewer doubts, more certainties. FEBS Lett 2019;593(13):1542-1553

Chaugule VK, Burchell L, Barber KR, Sidhu A, Leslie SJ, Shaw GS, Walden H. Autoregulation of Parkin Activity Through Its Ubiquitin-Like Domain. EMBO J 2011;30(14):2853-67

Cheng EH, Sheiko TV, Fisher JK, Craigen WJ, Korsmeyer SJ. VDAC2 inhibits BAK activation and mitochondrial apoptosis. Science 2003;301(5632):513-7

Choubey V, Cagalinec M, Liiv J, Safiulina D, Hickey MA, Kuum M, Liiv M, Anwar T, Eskelinen EL, Kaasik A. BECN1 is involved in the initiation of mitophagy: it facilitates PARK2 translocation to mitochondria. Autophagy 2014;10:1105-19

Chu CT, Ji J, Dagda RK, Jiang JF, Tyurina YY, Kapralov AA, Tyurin VA, Yanamala N, Shrivastava IH, Mohammadyani D, Wang KZQ, Zhu J, Klein-Seetharaman J, Balasubramanian K, Amoscato AA, Borisenko G, Huang Z, Gusdon AM, Cheikhi A, Steer EK, Wang R, Baty C, Watkins S, Bahar I, Bayir H, Kagan VE. Cardiolipin externalization to the OMM acts as an elimination signal for mitophagy in neuronal cells. Nat Cell Biol 2013;15:1197-205

Colombini M. Ceramide channels and mitochondrial outer membrane permeability. J Bioenerg Biomembr 2017;49(1):57-64

Criolo A, Vicencio JM, Tasdemir E, Maiuri MC, Lavandero S, Kroemer G. The inositol trisphosphate receptor in the control of autophagy. Autophagy 2007;3:350-53 
Csordás G, Várnai P, Golenár T, Roy S, Purkins G, Schneider TG, Balla T, Hajnóczky H. Imaging Interorganelle Contacts and Local Calcium Dynamics at the ER-mitochondrial Interface. Mol Cell 2010;39(1):121-32

De Brito OM, Scorrano L. Mitofusin 2 tethers endoplasmic reticulum to mitochondria. Nature 2008;456:605-10

Denton RM, McCormack JG. The calcium sensitive dehydrogenases of vertebrate mitochondria. Cell Calcium 1986;7(5-6):377-86

Ding WX, Ni HM, Li M, Liao Y, Chen X, Stolz DB, Dorn GW 2nd, Yin XM. Nix is critical to two distinct phases of mitophagy, reactive oxygen species-mediated autophagy induction and Parkinubiquitin-p62-mediated mitochondrial priming. J Biol Chem 2010;285(36):27879-90

Edlich F, Banerjee S, Suzuki M, Cleland MM, Arnoult D, Wang C, Neutzner A, Tjandra N, Youle RJ. Bcl-x(L) retrotranslocates Bax from the mitochondria into the cytosol. Cell 2011;145(1):104-16

Edlich F. BCL-2 proteins and apoptosis: Recent insights and unknowns. Biochem Biophys Res Commun 2018;500(1):26-34

Eno CO, Eckenrode EF, Olberding KE, Zhao G, White C, Li C. Distinct roles of mitochondria- and ER-localized Bcl-xL in apoptosis resistance and $\mathrm{Ca}^{2+}$ homeostasis. Mol Biol Cell 2012;23(13):2605-18

Foyouzi-Youssefi R, Arnaudeau S, Borner C, Kelley WL, Tschopp J, Lew DP, Demaurex N, Krause KH. Bcl-2 decreases the free $\mathrm{Ca}^{2+}$ concentration within the endoplasmic reticulum. Proc Natl Acad Sci U S A. 2000;97(11):5723-8.

Franke WW, Kartenbeck J. Outer mitochondrial membrane continuous with endoplasmic reticulum. Protoplasma 1971;73(1):35-41 
Funderburk SF, Wang QJ, Yue Z. The Beclin 1-VPS34 complex-at the crossroads of autophagy and beyond. Trends Cell Biol 2010;20:355-62

Gajkowska B, Wojewódzka U, Gajda J. Translocation of Bax and Bid to mitochondria, endoplasmic reticulum and nuclear envelope: possible control points in apoptosis. J Mol Histol 2004;35(1):11-9

Gao F, Chen D, Si J, Hu Q, Qin Z, Fang M, Wang G. The mitochondrial protein BNIP3L is the substrate of PARK2 and mediates mitophagy in PINK1/PARK2 pathway. Hum Mol Genet 2015;24(9):2528-38

Garofalo T, Matarrese P, Manganelli V, Marconi M, Tinari A, Gambardella L, Faggioni A, Misasi R, Sorice M, Malorni W. Evidence for the involvement of lipid rafts localized at the ERmitochondria associated membranes in autophagosome formation. Autophagy 2016;12:917-35

Gasser T. Genetics of Parkinson's disease. Curr Opin Neurol 2005;18(4):363-9

Gatliff J, Campanella M. The $18 \mathrm{kDa}$ translocator protein (TSPO): a new perspective in mitochondrial biology. Curr Mol Med. 2012;12(4):356-68

Gelmetti V, De Rosa P, Torosantucci L, Marini ES, Romagnoli A, Di Rienzo M, Arena G, Vignone D, Fimia GM, Valente EM. PINK1 and BECN1 relocalize at mitochondria-associated membranes during mitophagy and promote ER-mitochondria tethering and autophagosome formation. Autophagy 2017;13:654-69

Giacomello M, Pellegrini L. The coming of age of the mitochondria-ER contact: a matter of thickness. Cell Death Differ 2016 Sep 1;23(9):1417-27

Giorgio V, Guo L, Bassot C, Petronilli V, Bernardi P. Calcium and regulation of the mitochondrial permeability transition. Cell Calcium 2018;70:56-63 
Gomez-Suaga P, Paillusson S, Stoica R, Noble W, Hanger DP, Miller CCJ. The ER-mitochondria tethering complex VAPB-PTPIP51 regulates autophagy. Curr Biol 2017;27:371-73

Gotow T, Shibata M, Kanamori S, Tokuno O, Ohsawa Y, Sato N, Isahara K, Yayoi Y, Watanabe T, Leterrier JF, Linden M, Kominami E, Uchiyama Y. Selective localization of Bcl-2 to the inner mitochondrial and smooth endoplasmic reticulum membranes in mammalian cells. Cell Death Differ 2000;7(7):666-74

Hailey DW, Rambold AS, Satpute-Krishnan P, Mitra K, Sougrat R, Kim PK, Lippincott-Schwartz J. Mitochondria supply membranes for autophagosome biogenesis during starvation. Cell 2010;141(4):656-67

Hamasaki M, Furuta N, Matsuda A, Nezu A, Yamamoto A, Fujita N, Oomori H, Noda T, Haraguchi T, Hiraoka Y. Autophagosomes form at ER-mitochondria contact sites. Nature 2013;495:389-93

Hanada K, Kumagai K, Yasuda S, Miura Y, Kawano M, Fukasawa M, Nishijima M. Molecular machinery for non-vesicular trafficking of ceramide. Nature 2003;426(6968):803-9

Hansford RG. Physiological role of mitochondrial $\mathrm{Ca}^{2+}$ transport. J Bioenerg Biomembr 1994;26(5):495-508

Harner M, Körner C, Walther D, Mokranjac D, Kaesmacher J, Welsch U, Griffith J, Mann M, Reggiori F, Neupert W. The Mitochondrial Contact Site Complex, a Determinant of Mitochondrial Architecture. EMBO J 2011;30(21):4356-70

Hayashi T, Su TP. Sigma-1 receptor chaperones at the ER-mitochondrion interface regulate $\mathrm{Ca}\left({ }^{2+}\right)$ signaling and cell survival. Cell 2007;131(3):596-610

He H, Lam M, McCormick TS, Distelhorst CW. Maintenance of calcium homeostasis in the endoplasmic reticulum by Bcl-2. J Cell Biol 1997;138(6):1219-28 
Hoch FL. Cardiolipins and biomembrane function. Biochim Biophys Acta. 1992;1113(1):71-133

Horvath SE, Daum G. Lipids of Mitochondria. Prog Lipid Res 2013;52(4):590-614

Ichimura Y, Kirisako T, Takao T, Satomi Y, Shimonishi Y, Ishihara N, Mizushima N, Tanida I, Kominami E, Ohsumi M, Noda T, Ohsumi Y. A ubiquitin-like system mediates protein lipidation. Nature 2000;408:488-492.

Jacotot E, Costantini P, Laboureau E, Zamzami N, Susin SA, Kroemer G. Mitochondrial membrane permeabilization during the apoptotic process. Ann N Y Acad Sci 1999;887:18-30

Jeong H, Park J, Jun Y, Lee C. Crystal structures of Mmm1 and Mdm12-Mmm1 reveal mechanistic insight into phospholipid trafficking at ER-mitochondria contact sites. Proc Natl Acad Sci U S A 2017;114(45):E9502-E9511

Kirkin V, Lamark T, Sou YS, Bjørkøy G, Nunn JL, Bruun JA, Shvets E, McEwan DG, Clausen TH, Wild P, Bilusic I, Theurillat JP, Øvervatn A, Ishii T, Elazar Z, Komatsu M, Dikic I, Johansen T. A role for NBR1 in autophagosomal degradation of ubiquitinated substrates. Mol Cell 2009;33(4):505-16

Kissová I, Deffieu M, Manon S, Camougrand N. Uth1p is involved in the autophagic degradation of mitochondria. J Biol Chem 2004;279:39068-74

Kopec KO, Alva V, Lupas AN. Homology of SMP domains to the TULIP superfamily of lipid-binding proteins provides a structural basis for lipid exchange between ER and mitochondria. Bioinformatics 2010;26(16):1927-31

Kornmann B, Currie E, Collins SR, Schuldiner M, Nunnari J, Weissman JS, Walter P. An ERMitochondria tethering complex revealed by a synthetic biology screen. Science 2009;325:477-81

Kornmann B, Osman C, Walter P. The Conserved GTPase Gem1 Regulates Endoplasmic ReticulumMitochondria Connections. Proc Natl Acad Sci U S A 2011;108(34):14151-6 
Korsmeyer SJ, Shutter JR, Veis DJ, Merry DE, Oltvai ZN. Bcl-2/Bax: a rheostat that regulates an antioxidant pathway and cell death. Semin Cancer Biol 1993;4(6):327-32

Kozjak-Pavlovic V. The MICOS complex of human mitochondria. Cell Tissue Res 2017;367(1):83-93

Kuwana T, King LE, Cosentino K, Suess J, Garcia-Saez AJ, Gilmore AP, Newmeyer DD.

Mitochondrial residence of the apoptosis inducer BAX is more important than BAX oligomerization in promoting membrane permeabilization. J Biol Chem 2020;295(6):1623-36

Kwak C, Shin S, Park JS, Jung M, Nhung TTM, Kang MG, Lee C, Kwon TH, Park SK, Mun JY, Kim JS, Rhee HW. Contact-ID, a tool for profiling organelle contact sites, reveals regulatory proteins of mitochondrial-associated membrane formation. Proc Natl Acad Sci U S A 2020 Jun 2;117(22):1210912120

Lam M, Dubyak G, Chen L, Nuñez G, Miesfeld RL, Distelhorst CW. Evidence that BCL-2 represses apoptosis by regulating endoplasmic reticulum-associated $\mathrm{Ca}^{2+}$ fluxes. Proc Natl Acad Sci U S A. 1994;91(14):6569-73

Légiot A, Céré C, Dupoiron T, Kaabouni M, Camougrand N, Manon S. Mitochondria-Associated Membranes (MAMs) are involved in Bax mitochondrial localization and cytochrome c release. Microb Cell 2019;6(5):257-266

Lemasters JJ. Selective mitochondrial autophagy, or mitophagy, as a targeted defense against oxidative stress, mitochondrial dysfunction, and aging. Rejuvenation Res 2005;8:3-5

Liu L, Feng D, Chen G, Chen M, Zheng Q, Song P, Ma Q, Zhu C, Wang R, Qi W, Huang L, Xue P, Li B, Wang X, Jin H, Wang J, Yang F, Liu P, Zhu Y, Sui S, Chen Q. Mitochondrial outer-membrane protein FUNDC1 mediates hypoxia-induced mitophagy in mammalian cells. Nat Cell Biol 2012 $14: 177-85$ 
Mao K, Wang K, Liu X, Klionsky DJ. The scaffold protein Atg11 recruits fission machinery to drive selective mitochondria degradation by autophagy. Dev Cell 2013;26:9-18

Martins VM, Fernandes TR, Lopes D, Afonso CB, Domingues MRM, Côrte-Real M, Sousa MJ. Contacts in Death: The Role of the ER-Mitochondria Axis in Acetic Acid-Induced Apoptosis in Yeast. J Mol Biol 2019;431(2):273-288

Matsuda N, Sato S, Shiba K, Okatsu K, Saisho K, Gautier CA, Sou YS, Saiki S, Kawajiri S, Sato F, Kimura M, Komatsu M, Hattori N, Tanaka K. PINK1 stabilized by mitochondrial depolarization recruits Parkin to damaged mitochondria and activates latent Parkin for mitophagy. J Cell Biol 2010;189(2):211-21

Meier PJ, Spycher MA, Meyer UA. Isolation and characterization of rough endoplasmic reticulum associated with mitochondria from normal rat liver. Biochim Biophys Acta 1981;646(2):283-97

Mendes CC, Gomes DA, Thompson M, Souto NC, Goes TS, Goes AM, Rodrigues MA, Gomez MV, Nathanson MH, Leite MF. The type III inositol 1,4,5-trisphosphate receptor preferentially transmits apoptotic $\mathrm{Ca}^{2+}$ signals into mitochondria. J. Biol. Chem 2005;280:40892-900

Michel AH, Kornmann B. The ERMES complex and ER-mitochondria connections. Biochem Soc Trans 2012;40(2):445-50

Missiroli S, Bonora M, Patergnani S, Poletti F, Perrone M, Gafà R, Magri E, Raimondi A, Lanza G, Tacchetti C, Kroemer G, Pandolfi PP, Pinton P, Giorgi C. PML at Mitochondria-Associated Membranes Is Critical for the Repression of Autophagy and Cancer Development. Cell Rep 2016;16:2415-27

Modi S, López-Doménech G, Halff EF, Covill-Cooke C, Ivankovic D, Melandri D, Arancibia-Cárcamo IL, Burden JJ, Lowe AR, Kittler JT. Miro clusters regulate ER-mitochondria contact sites and link cristae organization to the mitochondrial transport machinery. Nat Commun 2019;10(1):4399 
Morré DJ, Merritt WD, Lembi CA. Connections between mitochondria and endoplasmic reticulum in rat liver and onion stem. Protoplasma 1971;73(1):43-9

Moulis M, Grousset E, Faccini J, Richetin K, Thomas G, Vindis C. The Multifunctional Sorting Protein PACS-2 Controls Mitophagosome Formation in Human Vascular Smooth Muscle Cells through Mitochondria-ER Contact Sites. Cells 2019;8(6):E638

Murakawa T, Yamaguchi O, Hashimoto A, Hikoso S, Takeda T, Oka T, Yasui H, Ueda H, Akazawa Y, Nakayama H, Taneike M, Misaka T, Omiya S, Shah AM, Yamamoto A, Nishida K, Ohsumi Y, Okamoto K, Sakata Y, Otsu K. Bcl-2-like protein 13 is a mammalian Atg32 homologue that mediates mitophagy and mitochondrial fragmentation. Nat Commun 2015;6:7527

Nakagawa T, Shimizu S, Watanabe T, Yamaguchi O, Otsu K, Yamagata H, Inohara H, Kubo T, Tsujimoto Y. Cyclophilin D-dependent mitochondrial permeability transition regulates some necrotic but not apoptotic cell death. Nature 2005;434(7033):652-8

Narendra D, Tanaka A, Suen DF, Youle RJ. Parkin is recruited selectively to impaired mitochondria and promotes their autophagy. J Cell Biol 2008;183(5):795-803

Narendra DP, Jin SM, Tanaka A, Suen DF, Gautier CA, Shen J, Cookson MR, Youle RJ. PINK1 is selectively stabilized on impaired mitochondria to activate Parkin. PLoS Biol 2010 ;8(1):e1000298

Novak I, Kirkin V, McEwan DG, Zhang J, Wild P, Rozenknop A, Rogov V, Löhr F, Popovic D, Occhipinti A, Reichert AS, Terzic J, Dötsch V, Ney PA, Dikic I. Nix is a selective autophagy receptor for mitochondrial clearance. EMBO Rep 2010;11(1):45-51

Oakes SA, Opferman JT, Pozzan T, Korsmeyer SJ, Scorrano L. Regulation of Endoplasmic Reticulum $\mathrm{Ca}^{2+}$ Dynamics by Proapoptotic BCL-2 Family Members. Biochem Pharmacol 2003;66(8):1335-40 
Pankiv S, Clausen TH, Lamark T, Brech A, Bruun JA, Outzen H, Øvervatn A, Bjørkøy G, Johansen T. p62/SQSTM1 binds directly to Atg8/LC3 to facilitate degradation of ubiquitinated protein aggregates by autophagy. J Biol Chem 2007;282(33):24131-45

Pavlov EV, Priault M, Pietkiewicz D, Cheng EH, Antonsson B, Manon S, Korsmeyer SJ, Mannella CA, Kinnally KW. A novel, high conductance channel of mitochondria linked to apoptosis in mammalian cells and Bax expression in yeast. J Cell Biol 2001;155(5):725-31

Pizzo P, Pozzan T. Mitochondria-endoplasmic reticulum choreography: structure and signaling dynamics. Trends Cell Biol 2007;17(10):511-7

Popgeorgiev N, Jabbour L, Gillet G. Subcellular Localization and Dynamics of the Bcl-2 Family of Proteins. Front Cell Dev Biol 2018;6:13

Prudent J, Popgeorgiev N, Bonneau B, Thibaut J, Gadet R, Lopez J, Gonzalo P, Rimokh R, Manon S, Houart C, Herbomel P, Aouacheria A, Gillet G. Bcl-wav and the mitochondrial calcium uniporter drive gastrula morphogenesis in zebrafish. Nat Commun 2013;4:2330

Ravikumar B, Moreau K, Jahreiss L, Puri C, Rubinsztein DC. Plasma membrane contributes to the formation of pre-autophagosomal structures. Nat Cell Biol 2010;12:747-57

Renault TT, Manon S. Bax: Addressed to kill. Biochimie 2011; 93(9):1379-91

Renault TT, Teijido O, Missire F, Ganesan YT, Velours G, Arokium H, Beaumatin F, Llanos R, Athané A, Camougrand N, Priault M, Antonsson B, Dejean LM, Manon S. Bcl-xL stimulates Bax relocation to mitochondria and primes cells to ABT-737. Int J Biochem Cell Biol 2015;64:136-46

Riekhof WR, Wu J, Jones JL, Voelker DR. Identification and characterization of the major lysophosphatidylethanolamine acyltransferase in Saccharomyces cerevisiae. J Biol Chem 2007;282(39):28344-52 
Rizzuto R, Pinton P, Carrington W, Fay FS, Fogarty KE, Lifshitz LM, Tuft RA, Pozzan T. Close contacts with the endoplasmic reticulum as determinants of mitochondrial $\mathrm{Ca}^{2+}$ responses. Science 1998;280(5370):1763-6

Robertson JD. The molecular structure and contact relationships of cell membranes. Prog Biophys Mol Biol 1960;10:343-418

Rusiñol AE, Cui Z, Chen MH, Vance JE. A unique mitochondria-associated membrane fraction from rat liver has a high capacity for lipid synthesis and contains pre-Golgi secretory proteins including nascent lipoproteins. J Biol Chem 1994;269(44):27494-502

Sandoval H, Thiagarajan P, Dasgupta SK, Schumacher A, Prchal JT, Chen M, Wang J. Essential role for Nix in autophagic maturation of erythroid cells. Nature 2008 Jul 10;454(7201):232-5

Schellenberg B, Wang P, Keeble JA, Rodriguez-Enriquez R, Walker S, Owens TW, Foster F, TanianisHughes J, Brennan K, Streuli CH, Gilmore AP. Bax exists in a dynamic equilibrium between the cytosol and mitochondria to control apoptotic priming. Mol Cell 2013;49(5):959-71

Schlattner U, Tokarska-Schlattner M, Rousseau D, Boissan M, Mannella C, Epand R, Lacombe ML. Mitochondrial cardiolipin/phospholipid trafficking: the role of membrane contact site complexes and lipid transfer proteins. Chem Phys Lipids 2014;179:32-41

Schweers RL, Zhang J, Randall MS, Loyd MR, Li W, Dorsey FC, Kundu M, Opferman JT, Cleveland JL, Miller JL, Ney PA. NIX is required for programmed mitochondrial clearance during reticulocyte maturation. Proc Natl Acad Sci U S A 2007;104(49):19500-5

Shamas-Din A, Brahmbhatt H, Leber B, Andrews DW. BH3-only proteins: Orchestrators of apoptosis. Biochim Biophys Acta 2011;1813(4):508-20 
Shiao YJ, Lupo G, Vance JE. Evidence that phosphatidylserine is imported into mitochondria via a mitochondria-associated membrane and that the majority of mitochondrial phosphatidylethanolamine is derived from decarboxylation of phosphatidylserine. J Biol Chem 1995;270(19):11190-8

Shkryl VM, Shirokova N. Transfer and tunneling of $\mathrm{Ca}^{2+}$ from sarcoplasmic reticulum to mitochondria in skeletal muscle. J Biol Chem 2006;281(3):1547-54

Stiban J, Caputo L, Colombini M. Ceramide synthesis in the endoplasmic reticulum can permeabilize mitochondria to proapoptotic proteins. J Lipid Res 2008;49(3):625-34

Stoica R, De Vos KJ, Paillusson S, Mueller S, Sancho RM, Lau KF, Vizcay-Barrena G, Lin WL, Xu YF, Lewis J. ER-mitochondria associations are regulated by the VAPB-PTPIP51 interaction and are disrupted by ALS/FTD-associated TDP-43. Nat Commun 2014;5:3996

Stone SJ, Vance JE. Phosphatidylserine synthase-1 and -2 are localized to mitochondria-associated membranes. J Biol Chem 2000;275(44):34534-40

Stone SJ, Levin MC, Zhou P, Han J, Walther TC, Farese RV Jr. The endoplasmic reticulum enzyme DGAT2 is found in mitochondria-associated membranes and has a mitochondrial targeting signal that promotes its association with mitochondria. J Biol Chem. 2009;284(8):5352-61

Stout BA, Melendez K, Seagrave J, Holtzman MJ, Wilson B, Xiang J, Tesfaigzi Y. STAT1 activation causes translocation of Bax to the endoplasmic reticulum during the resolution of airway mucous cell hyperplasia by IFN-gamma. J Immunol 2007;178(12):8107-16

Strappazzon F, Nazio F, Corrado M, Cianfanelli V, Romagnoli A, Fimia GM, Campello S, Nardacci R, Piacentini M, Campanella M, Cecconi F. AMBRA1 is able to induce mitophagy via LC3 binding, regardless of PARKIN and p62/SQSTM1. Cell Death Differ 2015;22:419-32

Sullivan DP, Ohvo-Rekilä H, Baumann NA, Beh CT, Menon AK. Sterol trafficking between the endoplasmic reticulum and plasma membrane in yeast. Biochem Soc Trans 2006;34(Pt 3):356-8 
Swiader A, Nahapetyan H, Faccini J, D’Angelo R, Mucher E, Elbaz M, Boya P, Vindis C. Mitophagy acts as a safeguard mechanism against human vascular smooth muscle cell apoptosis induced by atherogenic lipids. Oncotarget 2016;7:28821-35

Szabadkai G, Bianchi K, Várnai P, De Stefani D, Wieckowski MR, Cavagna D, Nagy AI, Balla T, Rizzuto R. Chaperone-mediated coupling of endoplasmic reticulum and mitochondrial $\mathrm{Ca}^{2+}$ channels. J Cell Biol 2006;175(6):901-11

Tan T, Ozbalci C, Brügger B, Rapaport D, Dimmer KS. Mcp1 and Mcp2, Two Novel Proteins Involved in Mitochondrial Lipid Homeostasis. J Cell Sci 2013;126(Pt 16):3563-74

Tatsuta T, Scharwey M, Langer T. Mitochondrial lipid trafficking. Trends Cell Biol. 2014;24(1):44-52

Teijido O, Dejean L. Upregulation of Bcl2 inhibits apoptosis-driven BAX insertion but favors BAX relocalization in mitochondria. FEBS Lett 2010;584(15):3305-10

Thomenius MJ, Wang NS, Reineks EZ, Wang Z, Distelhorst CW. Bcl-2 on the endoplasmic reticulum regulates Bax activity by binding to BH3-only proteins. J Biol Chem 2003;278(8):6243-50

Van der Vaart A, Griffith J, Reggiori F. Exit from the Golgi is required for the expansion of the autophagosomal phagophore in yeast Saccharomyces cerevisiae. Mol Biol Cell 2010;21:2270-84

Van Laar VS, Roy N, Liu A, Rajprohat S, Arnold B, Dukes AA, Holbein CD, Berman SB. Glutamate excitotoxicity in neurons triggers mitochondrial and endoplasmic reticulum accumulation of Parkin, and, in the presence of N-acetyl cysteine, mitophagy. Neurobiol Dis 2015;74:180-93

Vance DE, Walkey CJ, Cui Z. Phosphatidylethanolamine N-methyltransferase From Liver. Biochim Biophys Acta 1997; 1348(1-2):142-50 
Vance JE. Phospholipid synthesis in a membrane fraction associated with mitochondria. J Biol Chem 1990;265(13):7248-56

Vance JE, Shiao YJ. Intracellular trafficking of phospholipids: import of phosphatidylserine into mitochondria. Anticancer Res 1996;16(3B):1333-9

Vance JE. MAM (mitochondria-associated membranes) in mammalian cells: lipids and beyond. Biochim Biophys Acta 2014 Apr 4;1841(4):595-609

Vigié P, Cougouilles E, Bhatia-Kiššová I, Salin B, Blancard C, Camougrand N. The mitochondrial phosphatidylserine decarboxylase Psd1 is involved in nitrogen starvation-induced mitophagy in yeast. J Cell Sci 2019;132(1) pii: jcs221655

Volkmann N, Marassi FM, Newmeyer DD, Hanein D. The rheostat in the membrane: BCL-2 family proteins and apoptosis. Cell Death Differ 2014;21(2):206-15

Wei Y, Chiang WC, Sumpter R Jr, Mishra P, Levine B. Prohibitin 2 Is an Inner Mitochondrial Membrane Mitophagy Receptor. Cell 2017;168(1-2):224-38

Wild P, Farhan H, McEwan DG, Wagner S, Rogov VV, Brady NR, Richter B, Korac J, Waidmann O, Choudhary C, Dötsch V, Bumann D, Dikic I. Phosphorylation of the autophagy receptor optineurin restricts Salmonella growth. Science 2011;333(6039):228-33

Williams A, Hayashi T, Wolozny D, Yin B, Su TC, Betenbaugh MJ, Su TP. The non-apoptotic action of Bcl-xL: regulating $\mathrm{Ca}\left({ }^{2+}\right)$ signaling and bioenergetics at the ER-mitochondrion interface. J Bioenerg Biomembr 2016;48(3):211-25

Wu W, Lin C, Wu K, Jiang L, Wang X, Li W, Zhuang H, Zhang X, Chen H, Li S, Yang Y, Lu Y, Wang J, Zhu R, Zhang L, Sui S, Tan N, Zhao B, Zhang J, Li L, Feng D. FUNDC1 regulates mitochondrial dynamics at the ER-mitochondrial contact site under hypoxic conditions. EMBO J 2016;35(13):136884 
Xie Z, Klionsky DJ. Autophagosome formation: core machinery and adaptations. Nat Cell Biol 2007; 9:1102-09

Zhang A, Hildreth RL, Colberg-Poley AM. Human cytomegalovirus inhibits apoptosis by proteasomemediated degradation of Bax at endoplasmic reticulum-mitochondrion contacts. J Virol 2013; 87(10):5657-68

Zhu Y, Massen S, Terenzio M, Lang V, Chen-Lindner S, Eils R, Novak I, Dikic I, Hamacher-Brady A, Brady NR. Modulation of serines 17 and 24 in the LC3-interacting region of Bnip3 determines prosurvival mitophagy versus apoptosis. J Biol Chem 2013;288(2):1099-113

Zong WX, Li C, Hatzivassiliou G, Lindsten T, Yu QC, Yuan J, Thompson CB. Bax and Bak can localize to the endoplasmic reticulum to initiate apoptosis. J Cell Biol 2003;162(1):59-69 